\title{
DACRYOCYSTORHINOSTOMY*
}

\section{CLINICAL REPORT OF FIFTY CASES}

\author{
BY
}

\author{
G. J. ROMANES \\ From the Corneo-Plastic Unit and Eye Bank, Queen Victoria Hospital, \\ East Grinstead, Sussex
}

THE operation of dacryocystorhinostomy is an established procedure for the relief of epiphora. The watering may be due to blockage of the lacrimal drainage apparatus at any point from the sac to the nose, that is to say in the ampulla, the duct, or at the opening into the inferior meatus. The clinical indications for the operation are found in cases of persistent watering after :

(1) Failed probing.

(2) Chronic infection of the sac.

(3) Cicatricial stenosis in the lower part of the duct due to callus formation or scar shrinkage after fracture of the facial skeleton or extensive soft tissue lacerations.

(4) Occlusion of the opening of the duct into the inferior meatus of the nose in atrophic rhinitis and other affections of the nasal mucosa, and also in cases of chronic infection of the maxillary sinus or malignant disease of the antrum.

The aim of the operation practised in this Unit is to provide a physiological cure, since anatomical continuity as demonstrated by syringing is not a sufficient criterion of success. The principles of our operation conform to those of Dupuy-Dutemps (Arruga, 1952) and consist of anastomosis of the mucous membrane linings of the middle meatus of the nose and the lacrimal sac after excision of the intervening bony wall of the nose.

Investigations.-The routine procedure of investigation at this Unit includes a dacryocystogram and an ear, nose, and throat surgeon's opinion. The following special points are noted:

(1) The position and patency of the puncta.

(2) Syringing with a small lacrimal cannula is attempted, and in cases of doubt as to the patency of either canaliculus both upper and lower canaliculi are used in sequence.

(3) Should regurgitation occur along the upper canaliculus while syringing the lower, a pressure clip is appied to the upper one to help forcible filling of the sac. This procedure may show the presence of a stricture in the duct by preventing regurgitation. It is a useful method of showing up a low-lying block when doing a dacryocystogram to visualize the lower levels of the lacrimal duct. Without it the lipiodol may fail to pass the " air-lock", giving the false finding of a block in the sac.

All cases have a dacryocystogram taken after operation to confirm the presence of an anatomical opening. Should there be any loculi in the sac, these can be demonstrated and dealt with. The level of the bony stoma can be demonstrated and its position determined in relation to the nasal anatomy.

*Received for publication December 12, 1954. 
Special Points of Surgical Technique.-Several useful modifications have been added to the original technique of the operation at this clinic (Rycroft, 1951). The main features are the use of the Rycroft rhinostomy lamp for transillumination both before and during the operation. The lamp is inserted up the nose when the angular vessels can be seen with ease. Their outline is then marked with ink (Bonney's blue) on the skin, so that they can be avoided when making the incision. The area of maximum luminosity is noted and marked, for this will indicate the site of election for the bony excision. The proposed skin incision is drawn taking these points into account. The rhinostomy lamp is used again during the operation when the periosteum has been incised and reflected, in order to confirm the trephining site in the bone. At this stage with the assistance of the lamp it is possible to effect penetration into a low anterior ethmoidal air cell. The presence of this structure is shown by the relatively low illumination density observed. The use of the lamp also confirms that the nasal bony wall has been completely removed before the incision of its mucous membrane takes place. It is thus absolutely certain at all stages of the operation that a true rhinostomy has in fact taken place and that there has been no sidetracking into the ethmoidal cells. Further, it is possible to see the features of the sac with the aid of the light shining from inside the nose after it has been opened. Should there be any bleeding points, these can be picked up with ease with the help of the light. The position of the flaps of the sac can be planned accurately and placed in the most suitable position for that particular case.

The introduction of special needles by Rycroft (1951) has greatly facilitated the task of suturing the mucous membrane and sac flaps. These needles are based on the Denis Browne cleft palate needles and are five-sixths curved. They are stoutly made and measure one quarter of an inch between the point and the eye, being small enough to be manoeuvred within the limits of the lacrimal sac region.

It has been found that to obtain a good and imperceptible scar it is desirable to place the skin incision as anteriorly as possible on the side of the nose (Figure).

FIGURE.-Post-operative appearance showing anterior scar and catheter in position.

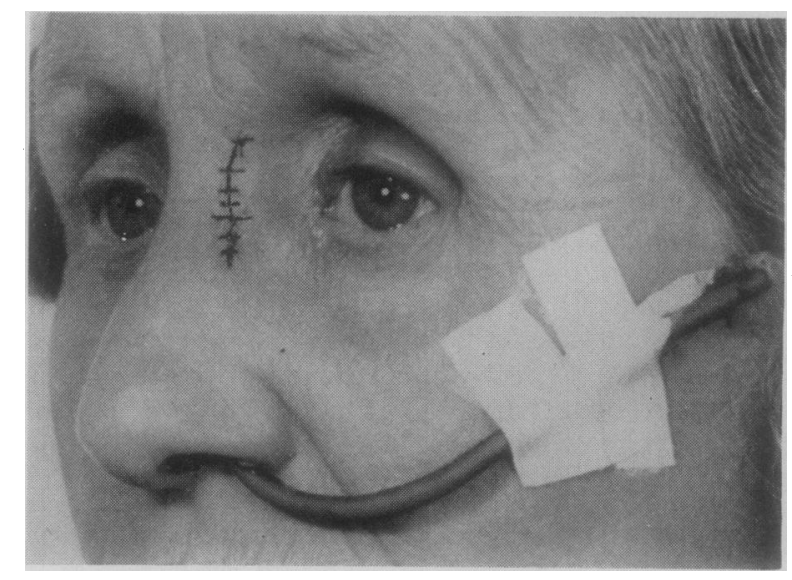

An incision placed posteriorly is under tension as it is crossing a relative cavity. This condition is responsible for a tendency to the formation of keloid. In addition shrinkage taking place when healing in this position produces a web effect, which is unsightly and has the appearance of a congenital epicanthal fold. The incision 
should also be straight and not curved, as any shrinkage on a straight line is subsequently imperceptible.

Modified Arruga lacrimal hand trephines (Rycroft, 1951) are used in all cases. The shank has been lengthened to allow the handle to clear the lids and to avoid pressure on the cornea and to obtain better visibility. The main advantage to be gained from the use of the trephines is that when the bony disk prolapses into the nose it does not cause adventitious laceration of the lining mucous membrane. Thus, when the fenestra has been enlarged with the Citelli punch, the anastomatic flaps can be planned to suit the anatomical conditions.

Hypotensive anaesthesia is in routine use in all adult cases which are passed as suitable by the anaesthetist for this technique (Enderby, 1950). Bleeding is reduced to a minimum and no sucker is needed at the operation. The healing is expedited and there is less oozing between the sutured flaps in the cystorhinostomy opening (Rycroft and Romanes, 1952). This technique assists the surgeon materially also in making the procedure a precise technique as opposed to a process hindered by sucker, swabs, or blood. Local anaesthesia is not used as it is difficult to obtain adequate infiltration of the scar tissue often found in cases seen at this Unit after general facial trauma. The large amount of fluid in the tissues not only alters their appearance and intimate physiology but also delays healing.

An important point of technique which in our view needs emphasis is the insertion of a No. 3 Jacques catheter in the fenestra. The funnel-shaped end of this catheter is sutured in the opening over the posterior flaps and the anterior flaps are connected across the front of the catheter which then supports the suture lines. The catheter is allowed to remain in position for a week. It is removed without difficulty and allows syringing to be instituted early in the post-operative course as well as preventing the accumulation of blood which might organize ultimately to occlude the opening.

\section{Results}

The cases under review were taken in sequence and are unselected. Fifty cases are reported. The Table shows the position of the block in the lacrimal drainage apparatus and an analysis of the figures. The clinical results are defined as those cases in which watering was cured. The cases which had a successful result anatomically in that they showed patency to syringing but which continued to be troubled by the symptom of epiphora for which they were originally referred are not counted as successful.

TABLE

RESULTS IN FIFTY CASES

\begin{tabular}{|c|c|c|c|c|}
\hline \multirow{2}{*}{ Site of Block } & \multicolumn{3}{|c|}{ Result } & \multirow{2}{*}{ Number of Cases } \\
\hline & Cured & Unimproved & Uncertain & \\
\hline $\begin{array}{l}\text { Sac } \\
\text { Duct }\end{array}$ & $\begin{array}{l}13 \\
26\end{array}$ & $\begin{array}{l}4 \\
1\end{array}$ & $\begin{array}{l}2 \\
4\end{array}$ & $\begin{array}{l}19 \\
31\end{array}$ \\
\hline Total Cases & 39 & 5 & 6 & 50 \\
\hline Percentage & 78 & 10 & 12 & 100 \\
\hline
\end{tabular}


The follow-up inquiry was well supported by the patients. Patients were asked whether they were free from watering and if not to supply the approximate date when the symptoms recurred. All the patients were seen at the clinic a month after their operation, again at 3 months, and finally at 6 months. The circular letter was sent out after more than a year had elapsed since operation, and replies to a questionnaire were received from all but six.*

Examination of these results shows that those cases in which epiphora was due to a block situated in the sac were the most difficult to treat successfully. In this category only four out of thirteen cases were unimproved. Epiphora due to a block in the duct was easier to treat in that 26 out of 31 of such cases were relieved. The reasons for the four failures were:

(i) one had a further plastic operation and watering recurred 6 months later;

(ii) two became blocked within the first post-operative month; as a second operation was not undertaken the reason remains conjectural but the probable cause was fibrosis of the small flaps obtainable;

(iii) one developed an acute coryza with secondary infection;

(iv) the case blocked after operation to relieve watering due to stenosis in the duct occurred in a child who had been in a motor accident.

In children the rhinostomy results are notoriously uncertain because of abnormal healing reaction due to vigorous growth of scar tissue. Both (iii) and (iv) were apparent within the first month.

The relatively high number of "uncertain" cases is largely due to the time that elapsed between operation and the investigation of the results. The clinical records show that they were all relieved for the first 3 months while they were visiting the hospital. It is only the absence of positive replies of cure that prevented them from being included in that group.

It is our opinion therefore that any patient who is relieved for 3 months can be considered as permanently cured. By this criterion the rate of cure is 45 cases in a series of fifty (90 per cent.).

\section{Summary}

(1) Results of dacryocystorhinostomy in fifty routine consecutive cases are reported.

(2) Points of technique of the operation which contributed especially to its success are emphasized.

(3) 90 per cent. of the cases operated upon were cured.

I wish to acknowledge the help I have received in the preparation of this paper from Mr. B. W. Rycroft, who also gave permission to use the material from cases referred to the Unit. I am indebted to Mr. Gordon Clemetson for the photograph.

\section{REFERENCES}

Arruga, H. (1952). "Ocular Surgery", trans. from 3rd Spanish ed. by M. J. Hogan and L. E. Chaparro, p. 248. McGraw-Hill, New York.

ENDERBY, G. E. H. (1950). Lancet, 1, 1145.

RYCROFT, B. W. (1951). British Journal of Ophthalmology, 35, 328. and Romanes, G. J. (1952). Ibid., 36, 29.

- Two patients returned an uncompleted form, one had been in approved school and his whereabouts were not known, one had gone abroad, and two letters were returned through the dead letter service. 


\section{NOTES}

\section{Faculty of Ophthalmologists}

Officers, 1955

At the Council meeting, the following officers were elected:

$\begin{array}{lll}\text { President - - } & - & \text { Dr. John Marshall } \\ \text { Immediate Past President } & \text { Mr. J. H. Doggart } \\ \text { Vice-Presidents - } & - & \text { Mr. T. K. Lyle, Mr. J. R. Wheeler } \\ \text { Honorary Secretary } & - & \text { Mr. E. F. King } \\ \text { Honorary Treasurer } & - & \text { Mr. A. McKie Reid }\end{array}$

\section{Ophthalmological Society of Egypt}

Officers, 1955

The following officers have been elected to form the Council:

$$
\begin{aligned}
& \text { President - - - Dr. Ismail Disouki } \\
& \text { Vice-President - - Dr. Fattouh Mohammed Fattouh } \\
& \text { Treasurer and Archivist Dr. Ahmad Abd El Rehim Fahmy } \\
& \text { Secretary - - - Dr. Sabri Kamel (Dar El Hekmah, } \\
& \text { Assistant Secretary - } \quad \begin{array}{c}
42, \text { Kasr El Ainy Street, Cairo) } \\
\text { Dr. Mohammed Tawfik Ismail }
\end{array}
\end{aligned}
$$

\section{Pan-American Congress of Ophthalmology}

THE Fifth Pan-American Congress of Ophthalmology will be held in Santiago, Chile, from January 11 to $17,1956$.

Dr. I. C. Michaelson, D.O.M.S., F.R.S.P.S., Ph.D., has been appointed Head of the Department of Ophthalmology at the Hadassah University Hospital and Professor of Ophthalmology at the Hebrew University-Hadassah Medical School, Israel.

\section{ERRATUM}

British Journal of Ophthalmology (1955), 39, 237. In the article entitled " Dacryocystorhinostomy " by G. J. Romanes, p. 238, 1. 11, for with read without. 